Recibido: 30 enero 2014

Aprobado: 06 marzo 2014

\section{TOWARDS A LIVABLE URBANIZED DELTA REGION. SPATIAL CHALLENGES AND OPPORTUNITIES OF THE PEARL RIVER DELTA*}

\author{
Diego Sepulveda Carmona** - Delft University of Technology, The Netherlands \\ Lei Qu**** - Delft University of Technology, The Netherlands \\ Yuting Tai****** - Delft University of Technology, The Netherlands
}

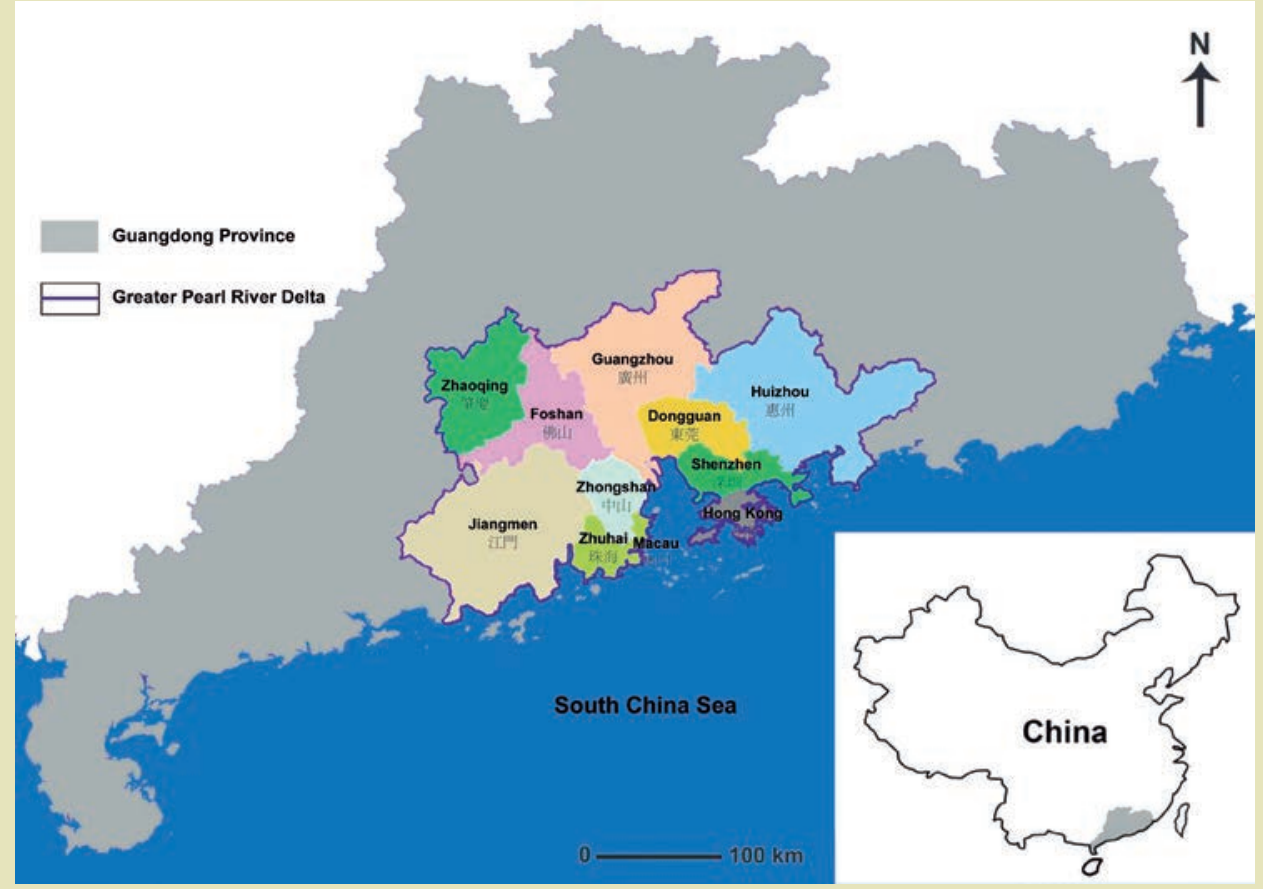

The Location of the Greater Pearl River Delto (GPRD)

Source: Leung Sze-lun, Alan, 2007.
Artículo resultado de investigación científica desarrollada por los autores dentro de "Randstad", Grupo de Investigación para la Planificación y Desarrollo del Territorio de la Delft University of Technology.

* Designer and urban planner. $\mathrm{He}$ is graduated from Pontifical Catholic University of Chile in 1996. He is Master in Urbanism from Delft University of technology in 1999. He received a PhD degree at the Department of Urbanism at the Architecture Faculty of Delft University of Technology (the Netherlands) in 2004. His research is focalize on evaluating the multi scalar interdependency of the spatial features at the regiona development, on relation to the development and impact of planning instruments relative to growing urban processes, socio-spatial effects and sustainable development. He focuses his work on regional development within developing economies, studying the case of the mega Cities (Buenos Aires, Sao Paulo, Jakarta, and Beijing). He is currently a researcher at Randstad Research Group for spatial planning and development at Delft University of technology. Correo electrónico:d.a.sepulvedacarm ona@tudelft.nl

\section{ABSTRACT}

The Pearl river delta (PRD) is now one of the emerging economic centres in the world, where economic development is associated with extremely rapid urbanization. This mega-region started to develop in the late 1970s with a rural industrialization model, which was designed to absorb surplus rural labor. Such a model contributed greatly to economic development of the region in the 1980s, but also caused serious environmental issues, such as water and air pollution, loss of farmland, as well as deterioration of the ecosystem and living environment. Nowadays, this mega-region is being restructured with regional infrastructures and new town development, so as to have a more compact urban and regional development model. These new spatial development strategies have the advantages of improving the efficiency of land use, and facilitating fast urbanization process. However, they also lead to large scale changes in natural conditions and have caused great alterations to water environment dynamics. A better coordination between spatial planning and water management systems is in urgent need, because it determines two major issues related to the pressures caused by rapid urbanization on the physical environment: increasing flood risks and environmental deterioration. This chapter describes the formation of the PRD mega-region and its impact on the water system and natural environment. Furthermore, it introduces the latest spatial development strategies for this region, defined at both national and regional levels, the key challenges to be tackled and recommendations towards a better operability.

\section{KEYWORDS}

Urbanization, Challenges, Strategies, The Pearl River Delta 


\section{HACIA UNA REGIÓN DELTA URBANIZADA HABITABLE. DESAFÍOS Y OPORTUNIDADES ESPACIALES DEL DELTA DEL RÍO PERLA}

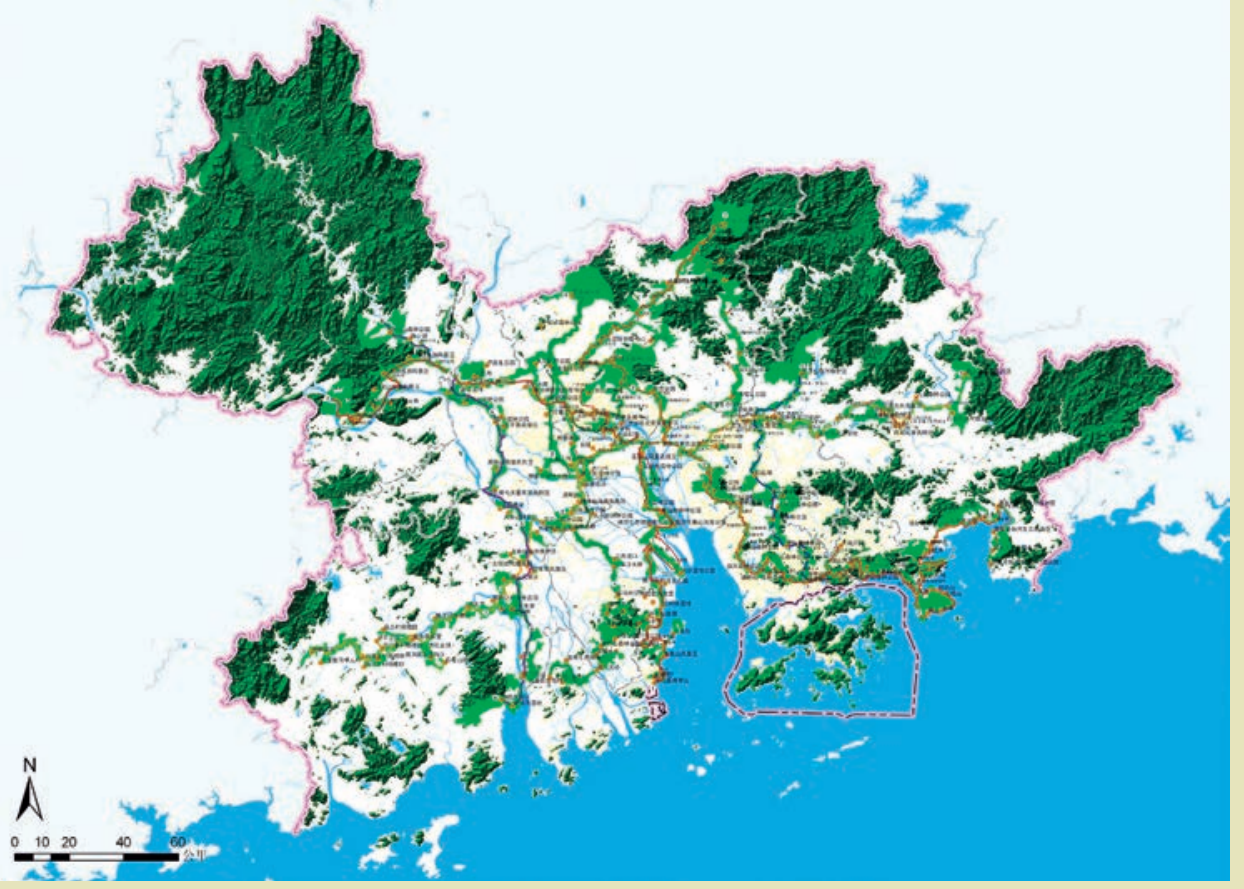

\section{RESUMEN}

El delta del río Perla (DRP) es ahora uno de los centros económicos emergentes en el mundo, donde el desarrollo económico está asociado con la urbanización extremadamente rápida. Esta mega-región comenzó a desarrollarse a finales de 1970 con un modelo de industrialización rural que fue diseñado para absorber la mano de obra rural excedente. Dicho modelo ha contribuido en gran medida al desarrollo económico de la región en la década de 1980, pero también causó serios problemas ambientales, tales como la contaminación del aire y del agua, la pérdida de tierras de cultivo, así como el deterioro del ecosistema y entorno de vida. Hoy en día, esta mega-región está siendo reestructurada con las infraestructuras regionales y el nuevo desarrollo de la ciudad, a fin de tener un modelo más compacto de avance urbano y regional. Estas nuevas estrategias de adelanto territorial tienen las ventajas de la mejora de la eficiencia de uso de la tierra, y facilitar el proceso de urbanización rápida. Sin embargo, también llevan a cambios a gran escala de las condiciones naturales y han causado alteraciones en la dinámica del medio ambiente acuático. Una mejor coordinación entre los sistemas espaciales de planificación y gestión del agua se necesita urgentemente, ya que determina dos aspectos importantes vinculados a las presiones causadas por la rápida urbanización sobre el medio físico: el aumento de los riesgos de inundaciones y el deterioro del medio ambiente. En este capítulo se describe la formación de la mega-región PRD y su impacto en el sistema de agua y el medio ambiente natural. Además, introduce las últimas estrategias de ordenación territorial para la región, que se define en los planos nacional y regional, los principales retos que deben abordarse y recomendaciones para lograr una mejor operatividad.
Greenway Planning in the Pearl River Delto Source: The Greenway Network Master Plan of the Pearl River Delta 2010, Issued by the People's Government of Guangdong Province.
*** Qu Lei. Delft University of Technology, The Netherlands. Doctor of Enginee- ring/posgrado. Assistant professor of Architecture Faculty DELF. Correo electrónico: I.qu@tudelft.nl
**** Yuting Tai. Delft University of Techno- logy, The Netherlands. PhD candidate in the Chair of Urban Design-Theory \& Methods within the Department of Urbanism of the Faculty of Architecture at the Delft University of Technology. Correo electrónico: y.tai@tudelft.nl

\section{PALABRAS CLAVE}

Urbanización, desafíos, estrategias, delta del río Perla. 


\section{INTRODUCTION TO THE PEARL RIVER DELTA}

The Pearl River Delta (PRD) is an economic zone in South China, which refers to an emerging large agglomeration in Guangdong Province covering 9 municipalities (including Guangzhou, Shenzhen, Zhuhai, Foshan, Jiangmen, Dongguan, Zhongshan, the urban areas of Huizhou and Zhaoqing). It is currently one of the most economically dynamic and densely urbanized agglomerations in the world, covering a total area of $41,698 \mathrm{~km}^{2}$, including a built-up area of $6,640 \mathrm{~km}^{2}$. The Greater Pearl River Delta (GPRD) is a larger region including the PRD economic zone and 2 Special Administrative Regions (SARs) of Hong Kong and Macau (figure I).

Figure I. The Location of the Greater Pearl River Delta (GPRD)

Source: Leung Sze-lun, Alan, 2007

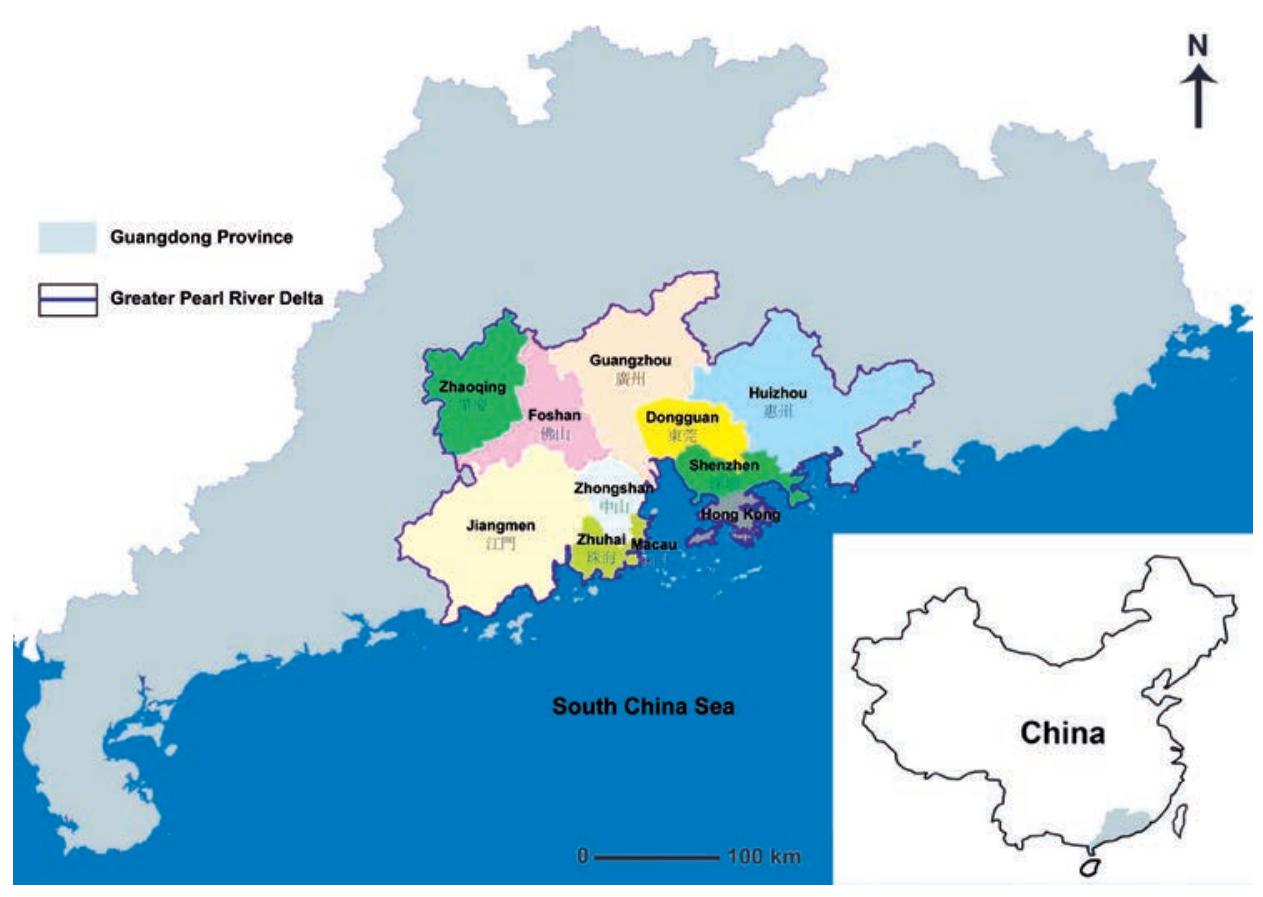

The complex water environment

The Pearl River Delta (PRD) is located in the low-lying land of the Pearl River estuary, where the branches of the Pearl River flow into the South China Sea. The same as many other deltas in the world, the Pearl River Delta was gradually formed by natural sediment deposition brought by river discharge during the last millennium, especially since the Ming Dynasty (late $14^{\text {th }}$ century). From a geomorphological perspective, the Pearl River Delta consists of three sub-deltas, namely Xijiang (West River), Beijiang (North River) and Dongjiang (East River) sub-deltas (figure 2). The subtropical climate and the monsoonal circulation of South China give rise to a total annual mean runoff of 300.4 billion $\mathrm{m}^{3}$ (Editorial board of the encyclopedia of rivers and lakes, 20I3). The water levels of the catchments are greatly influenced by the tides from the estuaries of the South China Sea.

The water environment of the PRD is characterized by its diverse and complex water system and water issues. Such complexity is mainly reflected in: the structure of the water 
network, with large number of crossings and estuaries; the hydrodynamic characteristics are influenced by runoff and tides at the same time; the dynamic transformations of waterways through time; the constantly changing of scope and intensity of the influence from human activities, etc. (Peng, et al., 2002). Changes of natural conditions and human activities have had serious influences on the water environment dynamics, which have not yet been well coordinated by the current spatial planning and water management systems. This has raised the issue of sustainable development in the PRD, namely the conflicts of economic development and preservation of water resources, when considering the carrying capacity of the water environment. To cope with such complexity, integrated spatial planning and water management is meaningful for the coordination of social, economic and environmental sustainability of the delta region as a whole.

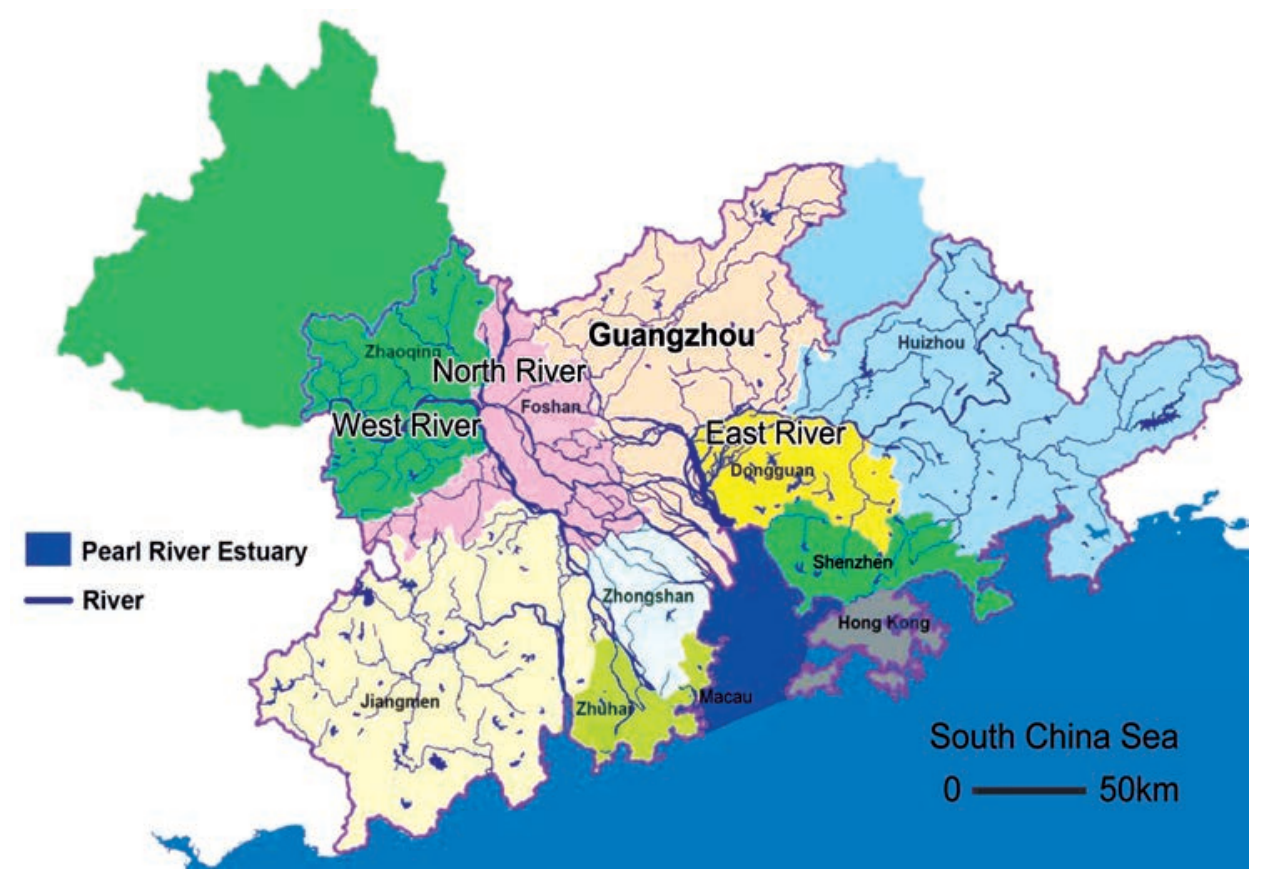

Currently, there are many other delta cities around the world facing similar challenges as the PRD. Facilitated by the CDC network (Connecting Delta Regions), dozens of these delta cities are sharing knowledge to keep their cities safe and livable, seeking for a "climate proof, resilient future for their residents and businesses" (http://www.deltacities.com/cities). The common characteristics of the strategies applied to the CDC network cities, basically can be defined as a search for integrating the developing strategies with the demands for climate change adaptation. However, the challenge and success of it still is based on the concrete design operability of each region to respond on its own institutional arrangement to this common perspective. The case of the PRD, is in another state of arts, given the fact that the challenge even though is recognized by the national and regional authorities, the integration of the strategies still needs to be institutionalized, as is described below: the key strategic goals are defined but need to reach a mature level for operationalization, so as to define concrete systems for implementation.
Figure 2. Water System in the Pearl River Delta Region

Source: Leung Sze-lun, Alan, 2007. 


\section{The changing urbanization model}

Historically the PRD was a grain-producing region in China, and farming played a dominant role in basic land use patterns until the 1980s (Indian National Science Academy, et al., 200I). Since the implementation of the national reform and opening up policy from 1978, the PRD region has experienced prosperous economic growth over the last three decades, which started with rural industrialization. This rural industrialization process was accompanied by rural urbanization in that the surplus labor from the countryside turned into a non-agricultural population without moving to cities. Furthermore, the labor market of the PRD was open to the whole country, attracting a large floating population from outside the region (Qu, Tai, Nadin, 20 I2). The population of the PRD therefore increased dramatically from 20.1 million in 1982 to 56.9 million in 20I2, which almost tripled within three decades (Guangdong Statistical Yearbook 2013). This does not include the data of Hong Kong and Macau. Without rapid expansion of large cities, the industrialization and urbanization processes before the late 1990s in the PRD were focused mainly on the rural areas (Lin, 1997), with spatial transformation from villages into towns and cities (Ma \& Lin, 1993; Wang, 1996; Guldin, 1997; Yan \& Liu, 1998). Such socio-economic transformation has brought significant changes to land use in the PRD. In 1982 farmland occupied 31.6 percent of the total area of the region, which is slightly less than the 33. I percent in 1973. This means that farming was still playing a dominant role at that time. However, this percentage dropped to 17.6 percent in 1995; while at the same time, the proportion of urban/ built-up land increased from 2.4 percent in 1973 to 15.7 percent in 1995. Influenced by the topography, most of the farmland and urban areas in the PRD are situated in the flatland; therefore the expansion of urban areas was at the expense of farmland (Indian National Science Academy, et al., 200I).

Since the 1990s, China has witnessed a significant transformation in the model of urbanization, and the market has become the most important driving force in propelling rural industrialization and urban development (Shen, Feng \& Wong, 2006). Besides, based on the "economic integration" efforts responding to Globalization, Chinese cities have become the country's engines for economic growth, in terms of attracting foreign direct investment. The goal of enhancing economic competitiveness has led to a shift in development focus, from urbanization based on small and medium sized cities to developing big cities and regions as growth poles, emphasizing more on regional cooperation, which eventually caused spatial restructuring on a regional scale.

In this context, Guangdong Provincial Government formed the Pearl River Delta Economic Zone in 1994. This political and economic approach followed national strategies in the 1980s, focusing on developing the coastal areas firstly, as the initial geopolitical experiment to speed up the process of economic reform. Benefitting from that, the PRD swiftly became China's first growth pole, and played a remarkable leading role in contributing to the country's overall socio-economic development. The PRD economic zone gained from its competitive locality, labor force, urban infrastructures and industrial chains, and is now one of the emerging economic centres in the world. The economic development was also associated with extremely rapid urbanization. By the end of 20I2, the urban population (47.7 million) accounted for $84 \%$ of the overall population ( 56.9 million) in the Pearl River Delta, and the GDP reached 4,778 billion RMB (approximately 764 billion US dollars), which constituted $9.2 \%$ of the national GDP of China in 2012 (Guangdong Statistical Yearbook 2013). 
To strengthen the economic connection with Hong Kong and Macau, another cross-boundary region "the Greater Pearl River Delta (GPRD)" emerged for regional cooperation and coordination, including the above-mentioned 9 municipalities and 2 Special Administrative Regions (Hong Kong SAR and Macau SAR).

\section{Industrial restructuring}

The PRD economic zone in Guangdong Province was characterized by its rural industrialization and fast urbanization process over the past three decades. Promoted by the economic reform in the late 1970s, township enterprises were largely developed in small towns and villages, which were mainly labor-intensive manufacturing industries geographically dispersed throughout the whole region. Whilst, in the early 1980s, the areas next to Hong Kong and Macau became the Special Economic Zones (SEZs) of Shenzhen and Zhuhai, respectively. With special regulations and taxation, these SEZs were expected to develop by attracting foreign investment. As a result, many labor-intensive industries were shifted from Hong Kong to the SEZs and other areas in the PRD, while Hong Kong retained the higher valueadded industries, such as international finance, logistics, design, R\&D, etc. (Qu, et.al, 20I2).

This rural industrialization model has contributed to economic development at a regional level and absorbed surplus rural labor in recent decades. However, the labor-intensive industry model and fast dispersed urbanization pattern has also caused serious environmental issues, such as water and air pollution, loss of wetlands and farmland, as well as the deterioration of the ecosystem and living environment. This can be illustrated as the phenomena triggered by lacking of proper treatment: industrial and domestic wastewater discharged into the river systems led to serious deterioration in river water quality, and posed a serious threat to drinking water sources. The river system therefore is not suitable for irrigation, aquaculture, and potential recreational uses (World Bank, 2007). Since the late 1990s, in response to such conditions, changes in industrial structures in the PRD region have occurred. Knowledge based industries, which are of higher added value but with lower energy consumption, started to replace the labor-intensive industries. (Qu, et.al, 20I2).

\section{The changing spatial structure}

After three decades of rural industrialization and urban development, the PRD region has witnessed a dramatic expansion in built up areas, which changed the urban-rural relationship to a great extent (figure 3 ). This could be seen as a spatial indication of rapid urbanization.

As indicated, due to the rapid expansion of urban areas, large amounts of productive farmland have been converted into built up areas. The amount of farmland decreased from $14,221.41 \mathrm{~km} 2$ in 1990 to $9,607.67 \mathrm{~km} 2$ in 2006 , which is $32.44 \%$ less in total (Ye and Dong, 2010). Currently, administrative boundaries are playing an important role in managing the territory of cities, which also set the limitation for urban expansion. To facilitate the growth of large cities that are restrained by the administrative boundaries, the surrounding county-level cities are merged into big cities as new urban districts, which could be regarded as a new strategy for urban expansion through a planned conurbation process. It could also be seen as an expression of a regional collaboration approach, which may reduce the amount of redundant construction within county-level cities, as well as the level of resource wasting, and environmental deterioration. Restructured in this way, the spatial pattern of the Pearl River Delta is becoming polycentric, with three growth poles 

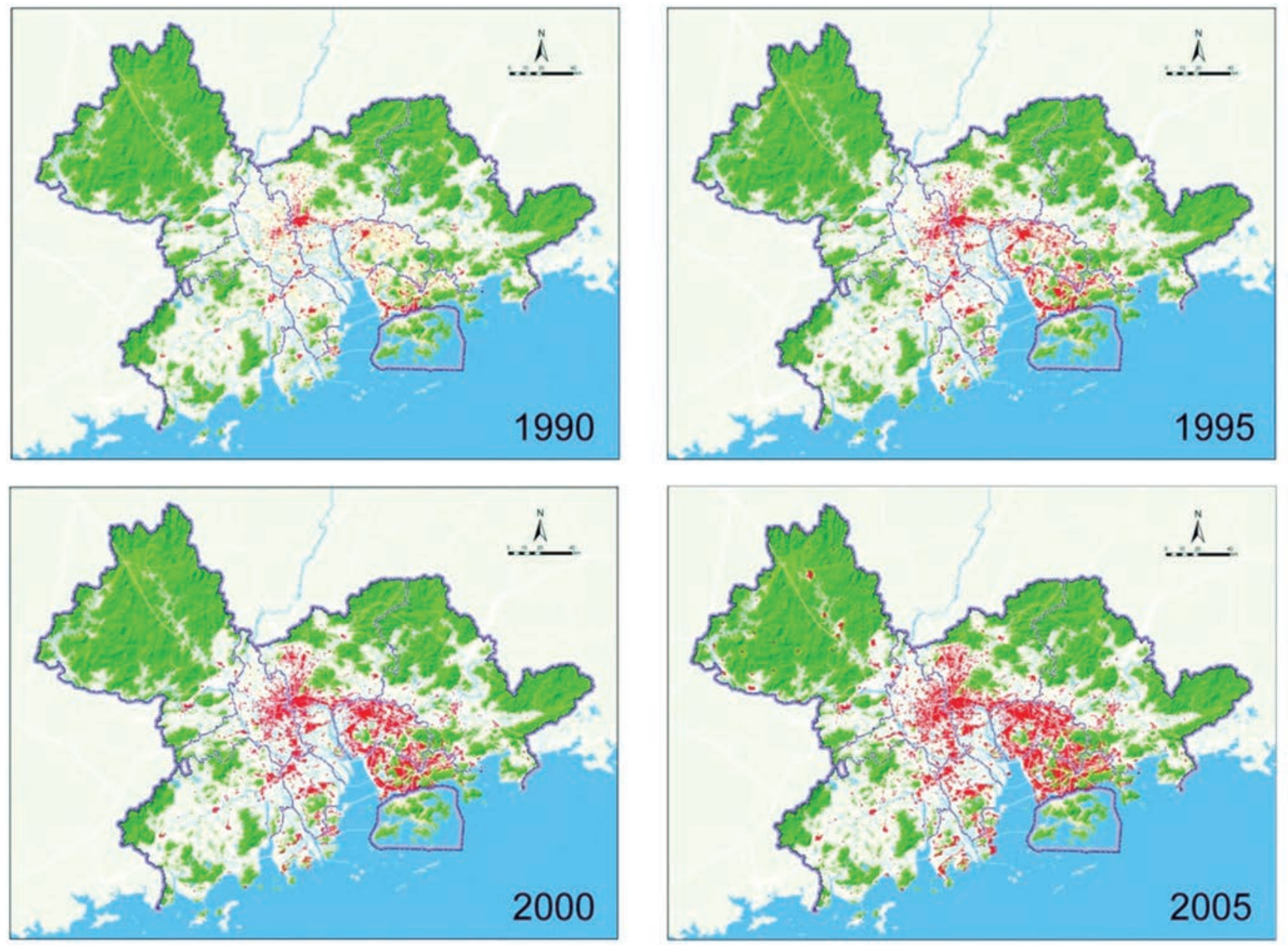

Figure 3. Urban Expansion of the PRD from 1990 to 2005

Source: Urban-Rural Integration Plan of the Pearl River Delta 2009-2020, Issued by the People's Government of Guangdong Province.

Figure 4. The Polycentric Development Pattern of the GPRD Region

Source: Planning Study on the Coordinated Development of the GPRD Townships 2006-2009.

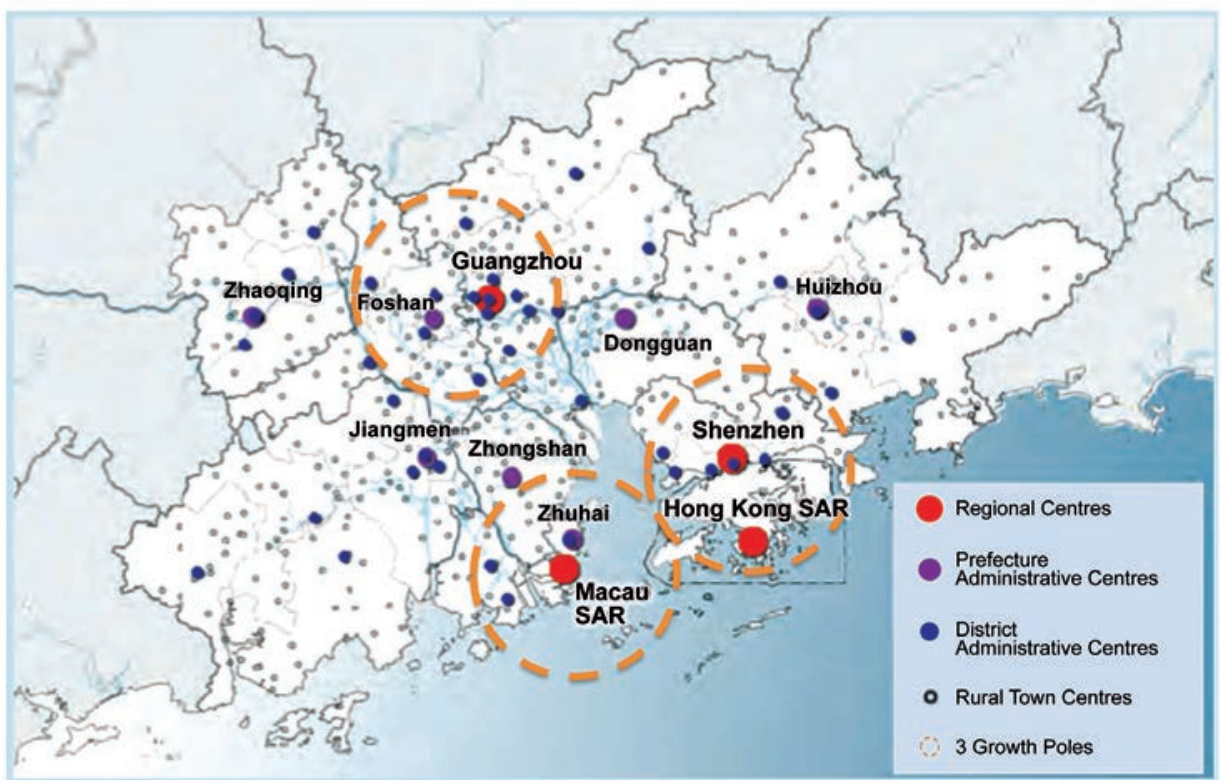


(Guangzhou - Foshan, Shenzhen - Hong Kong and Zhuhai - Macau), supported by a network of medium sized cities and small towns (figure 4). Transportation and other infrastructure networks are being considered as essential components shaping the spatial structure of metropolitan areas, as well as the consolidation of the region, especially along development corridors connecting the three main growth poles. Since the late 1990s, new plans for rearranging comprehensive transportation infrastructure networks were developed in the large cities like Guangzhou and Shenzhen. The well planned and developed highway system and intercity railway networks contributed greatly to the integration of small and medium sized towns within the regional city network, which brought greater chances for them to accommodate the shifting urban functions and population from the core cities. The roles of small and medium sized cities are changing due to the transformation of regional spatial structures, increasingly led by a "transit oriented development (TOD)" model (Qu, et.al, 20I2). Such regional network is being extended, connecting cities in other regions of China.

\section{CHALLENGES}

Along with the metropolization process, many mega cities in China are now facing a major challenge for urban development due to limited land resources (Seto \& Fragkias, 2005). Densification of the central urban area is associated with constraints on the expansion of the built-up area to accommodate population growth.

As the most densely occupied delta in the world, a highly dense agglomeration of over 100 towns and cities, the conflict between development pressures and limited space is even more intense in the Pearl River Delta. Due to the development of labor-intensive industry, there is an increasing demand for living space for the fast growing population, especially for the large share of floating population who settled down in the PRD parallel to a higher spatial demand by the rising middle class groups. At the same time, the delta has witnessed structural transformations in terms of land use. Along with continuous land reclamation towards the sea, many water and environmental issues have occurred due to the decrease of natural land and surface water system. There are two major issues related to the pressures caused by rapid urbanization on the physical environment: increasing flood risks and environmental deterioration.

\section{Flood risks and urbanization}

Although flooding is an inevitable natural disaster, the increasing flood risks in urban areas are associated with the unsustainable urbanization model. Abundant research has indicated that urban flooding is intensified by land use change (Wheater \& Evans, 2009). Along with urban growth, both spatially and demographically, the flood risks increase with more exposure. The urbanization process also alters local hydrologic characteristics (Montz, 2000). The natural water cycle is featured by high evaporation, high rate of infiltration, and low surface runoff. However, urbanization process changes natural surfaces to impervious artificial surfaces, which results in high storm water runoff rates and volumes, due to a declining natural water storage capacity of the soil. All these factors lead to increasing risks of urban flooding (WMO/GWP, 2007).

Being a low-lying delta and exposed to subtropical climate, the Pearl River Delta has historically been a region highly vulnerable to flood disasters. Generally speaking, the PRD is exposed to three types of flooding: fluvial flooding, pluvial flooding and coastal flooding. Along with the constructions of continuously strengthened water infrastructures like dikes, dams and reservoirs, the major flooding issue has gradually transferred from fluvial flooding 
Figure 5. Potential Flooding Areas of the Pearl River Delta with Current Flood Defense (Return Period of 100 Years)

Source: Based on the Data from China Nationa Marine Basic Information Network Service System. to more scattered pluvial flooding in densely occupied urban areas. Taking into account urbanization on coastal wetlands and the uncertainties of climate change, there is a growing trend of coastal flooding in the future.

Conventionally, flood issues are mainly tackled by hydraulic engineers through strengthening water infrastructures, while undermining spatial and environmental quality to some extent. For instance, inappropriate dike constructions and premature reclamation activities in the past led to severe environmental deterioration, such as deforestation, soil erosion, silting up of river channels and flooding. Dikes somehow changed the natural process of sedimentation, resulting in higher riverbeds. Therefore, dikes had to be heightened constantly to deal with higher water level, which caused higher flood risk (Li, 1998).

\section{Climate change}

There are two main undeniable driving forces, which have intensified the pressures on flooding. Besides the negative impacts of rapid urbanization and industrialization, climate change has attracted increasing attention in urbanized delta regions world-widely in recent decades due to their climate sensitivity.
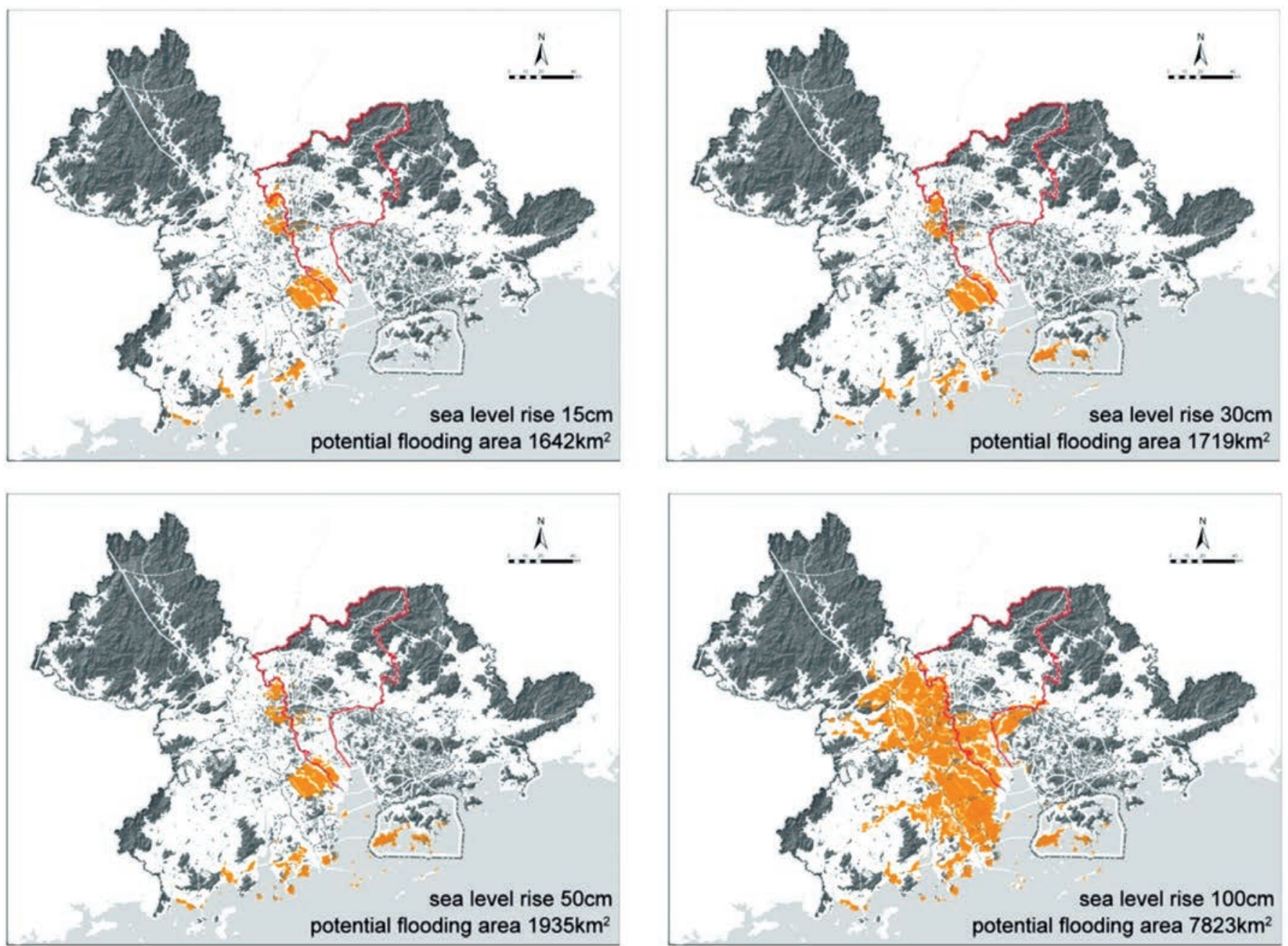
The Pearl River Delta is exposed to rising flood risks induced by climate change, especially rising sea levels, and extreme typhoons and storms in summer. The magnitude of mean sea-level rise in the PRD between 1990 and 2030 was predicted as $30 \mathrm{~cm}$ with an annual rising rate of $5 \mathrm{~cm}$ (Chinese Academy of Science, 2002). Occupying vast low-lying floodplain around sea level, the southern part of the delta is greatly threatened by the estimated consequences of climate change, as well as other uncertainties in the future (figure 5).

\section{Environmental issues}

As one of the most rapidly growing delta regions in the world, the Pearl River Delta has been developed with a long-term process of land reclamation towards the sea and rural urbanization. As mentioned earlier, driven by the national reform and opening-up policy in the late 1970s, the rural industrialization model and the dispersed urbanization pattern have generated enormous environmental and ecological problems.

Firstly, massive construction has led to overly rapid changes in ecosystems and farmland loss (Mee-kam, 2006). Since the 1980s, with the coastal fishponds and seashore being transformed into built-up areas, the mangrove ecosystem in Guangdong Province started to shrink. Damage to the mangrove ecology and resources by urban constructions happened in areas like Futian in Shenzhen (Xu \& Li, 2002). Furthermore, affected by human activities and new developments, the total area of wetland in the Pearl River Estuary coastal zone continued to decline (decreased 20,82I ha from 1986 to 1995, and 55,708 ha from 1995 to 2005 , accounting for $5.3 \%$ and $14.2 \%$ of the total area respectively) (Gao et al., 20I0). Secondly, being the "world factory", the labor-intensive industries in the Pearl River Delta also generated water pollution. Although there are abundant water resources in the PRD region, due to the water pollution and seawater intrusion, there is still a shortage of fresh water (Di et al., 2008). It has been estimated that the water supply deficit in the PRD region will increase in the near future. Finally, as new ports have been established at the Pearl River estuary, old industrial land and ports in old city centres have to face new functional transitions, determining a new agenda for sustainable urban transformation.

\section{SPATIAL STRATEGIES}

Facing the challenges of limited land resources and deteriorating natural environment, spatial strategies are in urgent need to accommodate the increasing population and new urban functions, and furthermore, strengthen its regional competitiveness in the global economy. In general, two types of interventions are responsible for the above-mentioned urban issues: spatial planning and water management. On the one hand, interventions based on the regional spatial planning strategies have been implemented for creating more space to accommodate increasing population on the floodplain. On the other hand, water management strategies have been taken to deal with water issues like urban flooding. These threats at both urban and regional levels, determine the challenges to the operability of territorial management. As for the PRD, the initiatives mainly come from the spatial planning side, mainly as guidelines for development, principally recognizing the necessity to consider the above-mentioned factors but not yet institutionalized them for integrated solutions. This is reflected by the latest planning documents presented as follows.

M 17 REVISTA M VOL. 11 No.1. ENERO-JUNIO 2014 • FACULTAD DE ARQUITECTURA • UNIVERSIDAD SANTO TOMÁs COLOMBIA 


\section{Spatial planning initiatives. The Outline of the Plan for the Reform and Development of the Pearl River Delta ("The Outline")}

Since 2008, strategic planning initiatives have arisen on the delta level addressing the above-mentioned urban issues. By the end of 2008 , an important plan "The Outline of the Plan for the Reform and Development of the Pearl River Delta (2008-2020)" was issued by the National Development and Reform Commission of China. "The Outline" explicitly regards the development of the PRD region as a national strategy for the first time. It also specifies that the PRD should perform as the pilot area to improve the regional integration of China. "The Outline" provides a comprehensive strategic framework to guide the overall coordinated and sustainable development of the PRD. With the strategic guidance, 5 integration plans of the PRD region were issued in accordance with the addressed issues in "The Outline":

- Infrastructure Development Integration Plan of the Pearl River Delta 2009-2020

- Industrial Distribution Integration Plan of the Pearl River Delta 2009-2020

- Basic Public Service Integration Plan of the Pearl River Delta 2009-2020

- Urban-Rural Integration Plan of the Pearl River Delta 2009-2020

- Environmental Protection Integration Plan of the Pearl River Delta 2009-2020

In dealing with environmental issues, as indicated in "The Outline", the PRD region will take the lead in building a resource conserving and environmentally friendly development framework. More specifically, it is targeted to reinforce the protection of farmland and ecological system, as well as to promote efficient utilization of resources (land, water, etc.). In this regard, the river mouth ecosystem, coastal swamps and mangrove forests will be effectively protected. The land obtained through filling and embanking the coasts will be utilized strictly for non-agricultural constructions. Following the plan guidelines, greenway planning is defined as a regional spatial strategy with multiple contributions. Since 2010, cities like Guangzhou and Shenzhen in the Pearl River Delta have been implementing greenway construction, aiming at regaining ecological value and facilitating slow traffic (figure 6). Many of these green corridors are arranged along existing canals, historical heritage, and green space, for enhancing the livability and resilience of the delta within a recognized green-blue network. This strategy not only improves the regional living environment, but also contributes to flood mitigation by reducing storm water runoff in these buffer zones.

\section{Planning Study on the Coordinated Development of the GPRD Townships (“The GPRD Study")}

Considering the coordination and cooperation between the Pearl River Delta and two Special Administrative Regions (Hong Kong SAR and Macau SAR), the "Planning Study on the Coordinated Development of the Greater Pearl River Delta (GPRD) Townships" ("The GPRD Study") was finished in 2009. It is the first strategic planning study undertaken with the agreement between the Hong Kong and Macau Affairs Office of the State Council and the governments of Guangdong Province, Hong Kong SAR and Macau SAR. Regarding spatial issues, "The GPRD Study" addressed 3 strategic goals concerning restructuring spatial structure of the GPRD region. 


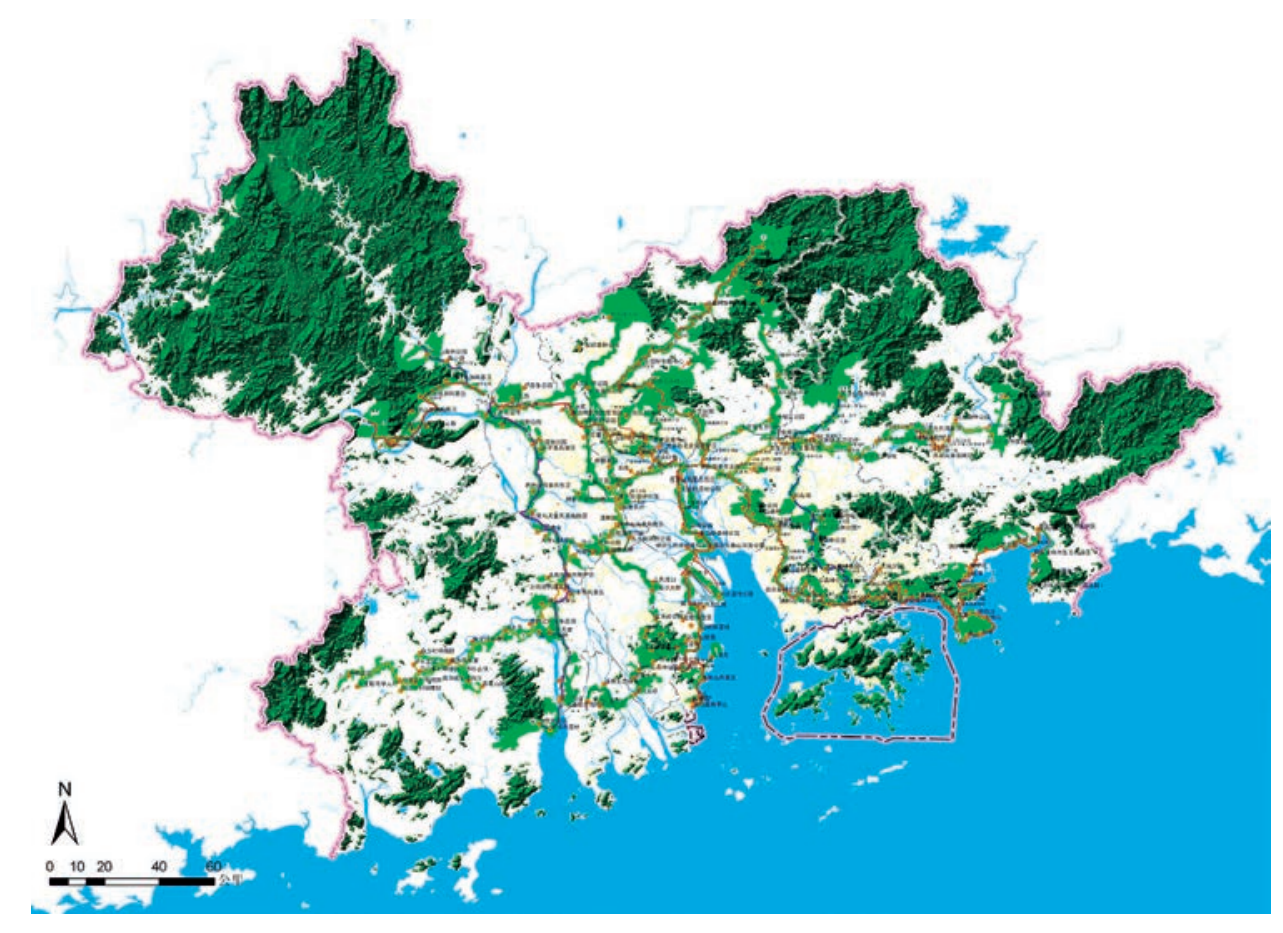

- Optimizing Spatial Structure

- Facilitating Regional Mobility

- Promoting Sustainable Environment

These strategic aims focus on building a coordinated and sustainable world-class region that is vibrant and globally competitive, while promoting a liveable and resilient living environment. Such cross-boundary coordination in regional development is quite similar to what is happening world widely, for example the EU Strategy for the Danube Region. The importance of preserving ecological sensitive zones is reinforced in the plan, especially the Bay Area where intensive urban development has been threatening the natural environment. To be specific, measures to be taken include: to ensure that proper planning and environmental impact assessments will be undertaken for large-scale developments before implementation; to raise the threshold for new industrial development; to implement the environmental mitigation measures before development; to exercise stringent monitoring and control on important environmental elements, such as air and water, as well as important habitats, such as wetlands ("The GPRD Study").

\section{Water management initiatives}

Although water (resource) management was mentioned in the general framework of regional strategic planning, there is still a lack of integration in terms of optimizing economic, ecological and social-cultural values. At the regional level, hydraulic authorities such as the Pearl River Water Resources Commission are mainly responsible for managing water resources and water infrastructures. To deal with flooding, the Pearl River Basin Flood Control Planning was issued in 2007. However, the flood control strategies mainly focused on concreting, deepening and straightening watercourses, including river regulation and channelization, as well as construction of embankments, which could undermine spatial quality and ecosystem. For example, construction of embankments destroys the living environment for riparian vegetation and freshwater organisms.
Figure 6. Greenway Planning in the Pearl River Delta

Source: The Greenway Network Master Plan of the Pearl River Delta 2010, Issued by the People's Government of Guangdong Province. 
In coping with such challenges, some integrated plans have been brought up for balancing the natural and built environments. The "Integrated River Basin Management (IRBM)" is one of such initiatives. In 2004, the China Council for International Cooperation on Environment and Development (CCICED) and the World Wide Fund for Nature (WWF) published a report entitled - "Promoting Integrated River Basin Management and Restoring China's Living Rivers". IRBM is a framework coordinating the management and development of the water, land, biological and related resources within a river basin to optimize the socio-economic benefits and environmental values in an equitable way. This is based on an ecosystem approach for conserving and repairing the freshwater ecosystems $(\mathrm{CCl}-$ CED Task Force, 2004). The concrete operability of this plan still needs to be reviewed comparing to "The Outline" framework, considering an integration on goals and strategies at the diverse governance levels involved.

\section{CONCLUSION}

\section{Summary on the challenges}

In conclusion, the Pearl River Delta has been experiencing increasing transitions and challenges from both urban development and environmental changes since the late 1970s. Given the fact that the PRD has been playing the leading role in propelling regional competitiveness under market driven forces since the 1990s, economic benefit is always given the priority in regional and local planning. However, it has been recognized that traditional labor-intensive industrialisation model and dispersed urbanisation pattern have caused many issues, regarding water safety, economic, social and environmental sustainability. Moreover, the current emerging mega-region structure reflected in rapid infrastructural development and land use transformation has seriously affected the water and environmental systems at large. Considering enormous socio-economic and climate uncertainties in the future, there is an urgent need to develop the whole region in a more resilient, adaptive and water sensitive way.

Although there have been several planning and water management initiatives tackling these issues on the regional level, the cooperation and coordination among the authorities of urban planning, environmental management and hydraulic engineering are still lacking. Taking into account the different governmental systems in the PRD and two SARs (Hong Kong and Macau), there is an increasing attention on the cross-boundary issues in the GPRD framework, such as regional transportation, water resource management and ecological preservation.

"The GPRD Study" perspective on the three main strategic goals represents the effort of regional development, but its operability remains uncertain, especially the extremely fast development of the region and pressures at the municipal level, where conflicts in development interests might occur.

\section{Recommendations}

Due to the competitiveness and cooperation dichotomies among cities within the PRD, strategic regional plans have to optimize values of the whole delta as a resilient and integrated system. The strategies have to deal with the challenges on both the delta and city scales. For the delta scale, the dynamics of topography and landscape determine the unique 
urban patterns in the PRD, which could be considered as rules of spatial transformation for regional planning. It is essential to take into account future challenges, and integrate various strategic goals at the diverse governance levels. It is crucial to adjust the functions of central mega cities in the network of different urban patterns. For instance, the development of regional infrastructures (both water and transport infrastructures) should be based on overall goals, as well as long-term impacts on regional to the smaller scale development perspectives on a local scale, whilst considering socio-economic and ecological values. For the city scale, urban planning and design is associated with local conditions, such as historical and cultural values, as well as the environmental carrying capacity. New development should be based on site-specific requirements instead of merely following the upper plans. Finally, more efficient cooperation among different levels of authorities, especially between spatial planning and water management sectors, is highly required. It is necessary to include a variety of actors to assess this challenge, as a way to support decision making process and effectively integrate the diverse responsibilities. This would activate the overall goals, and formulate a more integrated and resilient system in the region, throughout the diverse scale levels and including the whole spectrum of actors, from national to regional to local ones. Considering regional coordination and cooperation, a broader concept of the Greater Pearl River Delta Region could be further promoted, so that Hong Kong SAR and Macau SAR are also included in this regional vision.

\section{Planning documents}

The Outline of the Plan for the Reform and Development of the Pearl River Delta 2008-2020

Planning Study on the Coordinated Development of the Greater Pearl River Delta Townships 2006-2009

Infrastructure Development Integration Plan of the Pearl River Delta 2009-2020

Industrial Distribution Integration Plan of the Pearl River Delta 2009-2020

Basic Public Service Integration Plan of the Pearl River Delta 2009-2020

Urban-Rural Integration Plan of the Pearl River Delta 2009-2020

Environmental Protection Integration Plan of the Pearl River Delta 2009-2020

The Greenway Network Master Plan of the Pearl River Delta 2010

Urban Agglomeration Development Plan of the Pearl River Delta 2004-2020

Study on the Action Plan for the Bay Area of the Pearl River Estuary

Pearl River Basin Flood Control Planning

Canal Remediation and Restoration Plan of the Pearl River Delta

Guangdong Statistical Yearbook

M 21 REVISTA M VOL. 11 No.1. ENERO-JUNIO 2014 • FACULTAD DE ARQUITECTURA • UNIVERSIDAD SANTO TOMÁs COLOMBIA 


\section{REFERENCES}

China Council for International Cooperation on Environment and Development \& World Wildlife Fund for Nature (CCICED \& WWF). (2004). Promoting integrated river basin management and restoring China's living rivers. CCICED Task Force on Integrated River Basin Management, Beijing, P. R. China.

Chinese Academy of Science. (2002). The influence and strategy of sea level rise on coastal economy of Guangdong Province (Research Report) (in chinese).

Di, X., Sun, J., Jing, J. Huang, G. \& Chen, X. (2008). Features and factors of water environmental contamination in the Pearl River Delta Region. South to North Water Transfers and Water Science \& Technology, 6(4), 60-62 (in chinese).

Editorial board of the encyclopedia of rivers and lakes. (2013). Encyclopedia of rivers and lakes in China - section of the Pearl River Basin. Beijing: China Water \& Power Press, 277279 (in chinese).

Gao, Y., Su, F., Sun, X. and Xue, Z. (2010). On Changes in Landscape Pattern of Coastal Wetland around the Pearl River Estuary in Past Two Decades. Tropical Geography, 30(3), 215-220.

Guldin, G. E. (Ed.). (1997). Farewell to peasant China: rural urbanization and social change in the late twentieth century. Armonk, NY: ME Sharpe.

Indian National Science Academy, Chinese Academy of Sciences, U.S. National Academy of Science (200I). Growing Populations, Changing Landscapes: Studies from India, China, and the United States, National Academies Press, Washington, D.C.

Leung Sze-lun, Alan. (2007). Pearl River Delta scoping study, published by WWF Hong Kong SAR (Research Report). Retrieved from http://awsassets.wwfhk.panda.org/downloads/ prd_report_2007.pdf

Li, P. (1998). Recent flood and waterlogging calamities in the Pearl River Delta as viewed from geography. Pearl River (5), 56-58 (in chinese).

Lin, G. C. S. (1997). Red capitalism in South China: growth and development of the Pearl River Delta (2). Vancouver, British Columbia: UBC Press.

Ma, L. J., \& Lin, C. (1993). Development of towns in China: a case study of Guangdong Province. Population and Development Review, 19(3), 583-606.

Mee-kam, N.G. (2006). Sustainability impact assessment in the Pearl River Delta Region: problems and possibilities. In Yeh, A., Sit, V., Chen, G., \& Zhou, Y. (Eds.). Developing a competitive Pearl River Delta in South China under one country-two systems, (pp. 309-333). Hong Kong: Hong Kong University Press. 
Montz, B. E. (2000). The generation of flood hazards and disasters by urban development of floodplains. Floods, I, II6-I27.

Peng, J., Liao, W., He, S. \& Li, J. (2002). The preliminary research on the carrying capacity of the water environment and the coordinate regulation in the Pearl River Delta. In the proceedings of the seminar: Carrying capacity of water resource and water environment, Weihai (in chinese).

Qu, L., Tai, Y., Nadin, V. (20I2). The changing scale and spatial structure of chinese city regions a case study on the development of Panyu district in Guangzhou metropolitan area. $6^{\text {th }}$ International Association for China Planning Conference (IACP).

Seto, K. C., \& Fragkias, M. (2005). Quantifying spatiotemporal patterns of urban land-use change in four cities of China with time series landscape metrics. Landscape Ecology, 20(7), 87I-888.

Shen, J., Feng, Z., \& Wong, K. Y. (2006). Dual-track urbanization in a transitional economy: the case of Pearl River Delta in South China. Habitat International, 30(3), 690-705.

Wang, S. (Ed.) (1996). Studies on regional development of urbanization in China. Beijing: Higher Education Press (in chinese).

WMO/GWP (2007). The role of land use planning in flood management - a tool for integrated flood management. WMO/GWP Associated Program on Flood Management.

Wheater, H., \& Evans, E. (2009). Land use, water management and future flood risk. Land Use Policy, 26, 25I-264.

World Bank (2007). World Bank Helps Clean Up China's Pearl River. Press Release N. ${ }^{\circ}$ 288. EAP.

Xu, Y., \& Li, S. (2002). The negative impacts of urban construction on the mangrove ecological resources and protection measures in Futian, Shenzhen. Resources and Industries, 3, 32-35 (in chinese).

Yan, X., \& Liu, X. (1998). The mechanism and regulation of rural urbanization in the Pearl River Delta. In: Xu, X. Q., Sit, V. F. S., \& Yan, X. P. Rural-urban transition and coordinated development in China, 294-30I. Beijing: Science Press.

Ye, C. and Dong, Y. (2010) Effects of Land Use Change on Ecosystem Service Value of the Pearl River Delta. Tropical Geography, 30(6), 603-608. 